\section{ON THE TREATMENT OF DETACHMENT OF THE RETINA:}

Communication addressed to the Académie de Medecine of Paris, October 1.4h , 1884

BY J. R. WOLPE; M.D., F.R.C.S.E.,

Surbedon to the Glasgow Ophthalmic Institution, 'Lecturer on' 'Opthatimology in Anderson's College.

T HAVE the honour to present to the Academy a method of treatment in cases of detachnent of the retina, an affection which has hitherto gen regarded by all oculists as incurable. Various means, of both medical and surgical treatment, have been tried, but have been all abandoned as unfitted to cope with that disease. As I have frequently ifucceedted in caring'patients of detachment of the retina; I am desirous of submitting my mode of treatment for the consideration of the Acadeny.

1. Detachment of the retina is produced by an effusion of serum betwoen that membrane and the choroid.. The retina thus becomes intakled and separated, is broughtin front of the focis of the dioptric system, and can easily be seen by the erect ophthalmoscopic iimage, In the first stage, it shows only a slight undulation. When further advanced, a pale grey elevation becomes visible, which, when the eye is in motion, screens a part of the fundus, and the vessels are seen crossing the surface of the detached portion. This igrey opaqne body gradually increases in size, and the subretinal fluid accumulates, Iuntil po part of the fundus can be seen. Totsl loss of vision.:then ensues, and the detachment is said to be complete.

The subjective symptoms are, first, dimness of vision, the patient aipg; as it were, a cloud before him ; secondly, the interruption of the visual field, that is, the patient sees when looking in one direction, btut, when looking in another direction, a cloud seems to intervene between him and the object. In looking at the light of a lamp, the colbur appears of a blue tinge. When the offusion approaches the macula, objects appear crooked, and when, the macula itsolf becomes involited, the optic axis deviates : in another direction. When the of fusion has once commenced, it continues to develop itsolf until the whole visual field is abolished, and the patient cannot distinguish the light of a.candle moved before him in any direction.: It is worthy of note that, in some cases of extensive effusion, even that part of the wetina which is in situ, and still visible by the ophthalmoscope, loses to sensibility to light, because it.seems to have, to some extent, im bibed the fluid from the other part.

1/The description just given is that of the acute form of the affection, which, whether it follow a more or less rapid course in its development, may be traced to a chill caused by a sudden exposure to cold wile heated. As a typical case, may be mentioned that recorded by Desmarres, of a lady of distinction, who, in coming from a ball at the Hotel de Ville on a frosty night, was unable to find her cloak. Too impatient to wait for it, she walked with bare head and shoulders to "ithe carriage, and was instantly taken with detachment of the retina of the right eye. (Mfaladies des Yeux, vol. iii.). This acute form may also supervene upon either a single attack, or a succession of attacks, of violent epistaxis. The.vascular relation between the arterit contralis retinæ, and the orbital and frontal arteries on the on fiand, 1 rand the Schneiderian membrane on the other, in the case of chill to an overheated face and neck, sufficiently accounts for the pheromena in question ; but continued epistaxis may also: be the consoquence, rather than the cause, of the retinal congestion and detachwiont. Further, instead of a simple stretching of the'retina, a part of ot may be torn away, and float as a flap in the vitreous humiour.

The detachment more frequently follows a chrovic coturse, and may take two or three years for its development; and in such cases the fivid, instead of being transparent pure serum, is mixed with pigmentgtianules, and sometimes, though 'rarely, with white'flocculi. 'Phis chrotic state is caused by acute'irido-choroiditis, irido-cyclitis, or, inded, by any of the various forms of chrovic intra-ocular inflammation. It is very fortunate if the inflammation be confined to the membranes. ahd leaves the vitreous body nninvolved, for otherwise tho lons ultimately particlpates, and the result is softening and atrophy of tho globle. Sometimes, spontaneous intra-ocular hamorrthago and total disorganisttion of the eyeball may take place. ${ }^{1}$

1 Thile revising this paper, I have again seen the case (Sylugtor $t$ ) o dichile revising this paper; I have again seen the case (Sylvegter. H.) ghown to

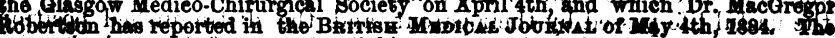

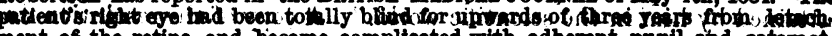

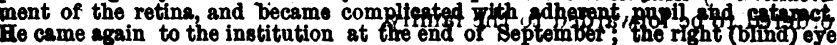

Associated with the chronic form of detachment of the retina we most frequently have high degree of myopia, which state of refraction, in fact, goes hand in hand with the intra-ocular pathological conditions just mentioned.

Detachment of the retina may, however; also be traumatic in its origin. I have at present 'under observation the case of Admiral _ , who, when out shooting in November 1879, was struck in the right eye by a pellet from the gun of one of the party. I extradted the pellet, which was lodged under the conjunctiva, and had made an indentation in' the sclerotic. The eye remained perfectly well February 1880, when, after being out on the ice curling during the day, he ihad the same evening an attack of epistaxis, so vialent: that a besin was : completely filled with blood, from the right nostril. Irido-choroiditis, with detachment of the retina, followed some days later. The inflammatory attack left a posterior synechia behind, and the detachment gradually increased. I may also mention that the detachment may either be continuous, or in isolated spots or portions." When the detachment is large, it is generally situated in the lower parition. Even when it begins at the upper portion, it for the most part gravitates dowuwards; and the part of the retina originally affected, if the layer of rods and cones have not been long macerated, applies itself again upon the choroid, and' reasermes its function. My clinical observations have fully convinced the of that fact.

Treatinent. - In iny opinion, this effusion engtht to be treated in the same way as other effusions in serous cavities, as, for example, in the pleura or in the peritoneum. I withdraw the effused fluid by a subconjunctival sclerotomy; practised in the meridional direction. The following are the differentisteps in my operation, when there is a large continuous detachment of the retina, and vision is Hearly or entirely 'abolished, I examine the patient by the erect ophthalmoscopic image, in order to ascertain the sito of the detachment; and also to which side the effused fluid inclines. It is essential to repeat this examination, putting the patient's head in different positions. Thus, with the patient sitting upright, and then, also, with the head placed in a horizontal pesition, he is made to look upwards and downwards, to the right and to the left. The side to which the fluid inclines in the different positions of the eyeball having been thus ascertained, the patient is put under chloroform, and the ophthalmostat is introduced. I then make a vertical incision into the conjunctiva, half an inch long, in the region of the detachment. The assistant separates the lips of the wound in a horizontal direction, by means of two strabismus-hooks. I then open Tenon's capsule, lay bare the sclerotic, and rotate the eyeball in such a direction as to expose the corresponding part of the sclerotic, towards which the fluid inclines. Into that part, I introduce a broad needle, having an external flat surface, and an internal convex surface, and thus give the incision a curved form. ${ }^{2}$ The needle is gently withdrawn without the slightest inclination, and the liquid flows on the withdrawal of the instrument. The instrument is introduced obliquely, in such a manner that the edges of the scleral wound should overlap each other, and not remain gaping when the instrument is withdrawn. If I judge that more fluid remains behind, I introduce a fine silver spatula, and press gently on the lips of the scleral wound. But if the detachmint be not very extensive, or the eyeball too promipent, or, rather, soft I operate with a flat sclerotome, so as to produce a linear, instead of a curved, incision.

The lips of the conjunctival wound are now brought together by means of one or two fine silk-ligatures (although, in exceptional cases, these ligatures may be dispensed with), and both eyes are shut by three strips of court-plaster, lint, and a bandage. The patient is ordered to lie upon his back for two or three days, as after the extraction of cataract. On the third or fourth day, I renew the simple dressing, without opening the eyes ; but, on the fifth day, the eyes are opened, and the remults of the operation ascertained. By this time, there is generally not the slightest trace of an operation left, so that this method is, at all events, inoffensive, even if we do not always obtain the desired result. Generally, however, we obtain satisfactory results. Of seven operations which have been recorded from my clinique since 1878, three have resulted in perfect success. The state of total blindiness in each has been curced, so that the patients could retiurn to their ordinary occupations. In each of four other cases,

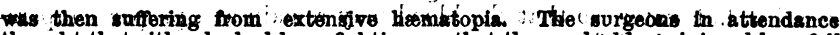

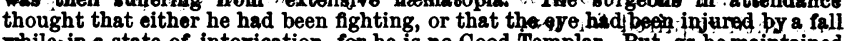
while in a state of intoxicstion, for he, is no Goad Templar. But \&s he maintsined thithe had not been' Aghting, nor met with and accident, and as there was no

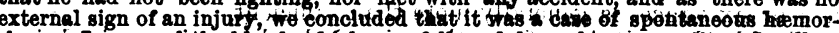

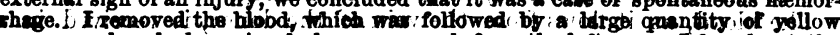
serpm such as had previgugl, been femored, from the laft, eye, Ifound, at the

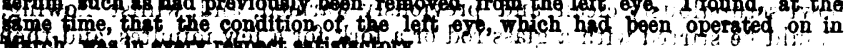

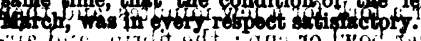

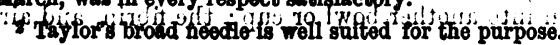


there was a decided improvienent; ; the pationts could to walk: about, although sight was not completely restored.

Eight days ago, in the ophthalmic hospital of Paris, I operated upon a patient under the following circumstances. For the report of the case, I am indebted to Dr. Henri Campart.

Madame B., aged 57, came to the:Olinique Nationale Ophthalmologique des Quinze Vingts, July 12th, 1884. She stated that; in the previous April, she frequently noticed shadows floating before her right: eye. Every object that she looked at attentively appeared to her surrounded by coloured rings, especially if the objects were in a bright light. She had never been myopic, and, three months previously, the sight of the right eye was quite as good as that of the left. A few days afterwards, in getting up one morning, she found that the sight of the right eye had become considerably impaired, and that in a very rapid manner. Objects appeared to her crooked, and she could not distinguish their lower half. She felt a sense of weariness in using the eyes but there was no spontaneous pain. Dr. Galezowski, when consulted some days later, as to this anomaly of vision, found a detachment of the retina of the right eye. He ordered cold compresses to the eye, and blister and leeches to the right temple, and a collyrium of sulphate of eserine ( 5 centigrammes to 10 grammes of distilled water). Having received no benefit from this treatment, the patient presented herself at the Quinze Vingts, on the date above mentioned. She is a stout, plethoric woman, and stated that she had long suffered from asthma, attacks of which occurred several times a week. Her occupation was that of a laundress, and she had evidently been much overworked. Dr. Fieuzal diagnosed the case as detachment of the retina of the right eye, with glaucomatous excavation of the optic nerve; with the right eye; she could count the fingers at 58 inches distance; with the left eye, vision was $\frac{2}{3}$ of Wecker's types.

Treatment. - A solution of sulphate of atropine (1 in 200) was dropped. into the right eye, and sulphate of eserine into the left. Iodide of potassium was also prescribed to be taken before each meal. At the beginning of October it was proposed to her that she. should undergo an operation; she assented, and the operation was : fixed for October 7th, 1884 .

With the authority of Dr. Fieuzal, , chief surgeon of the hospital, who assisted at 'the operation, an anxisthetic was

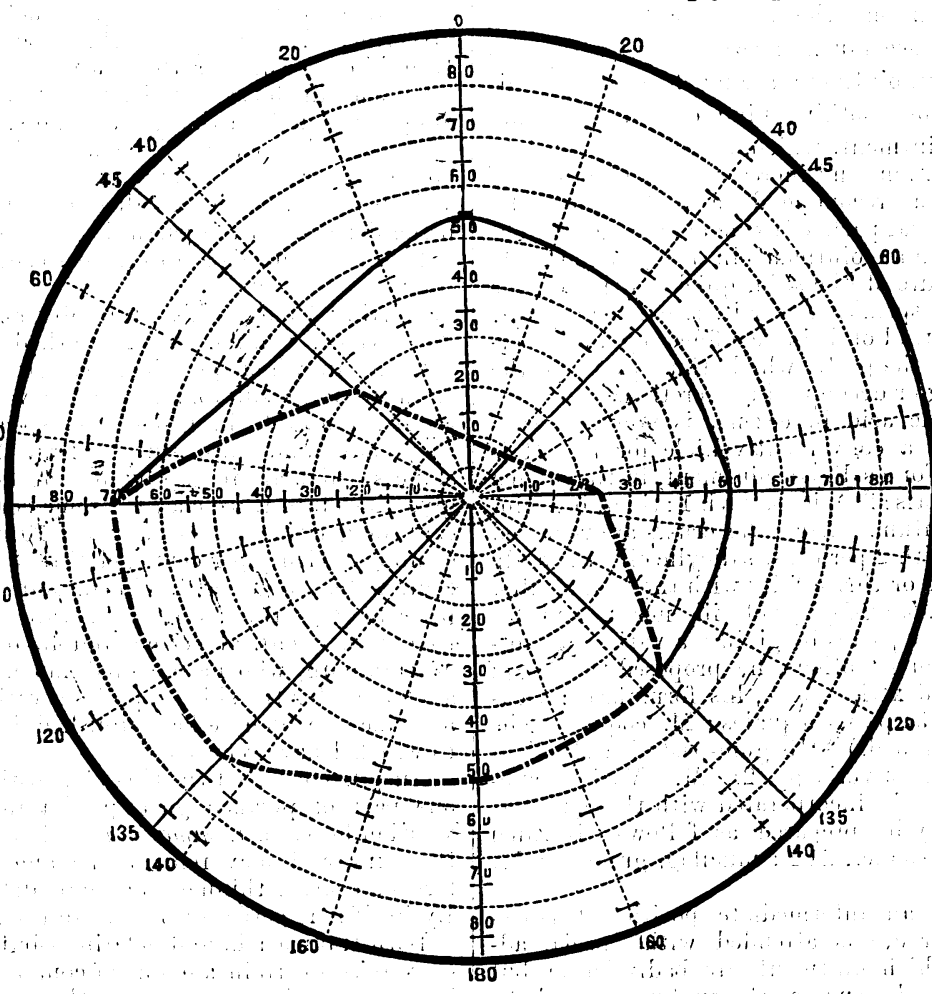

The dbtted line marks the botundary of the visual field before, and the continned line shows the gain after, the operation.

given, and Dr. Wolfe performed paracentesis of the selerotic. The lids were kept widely open, and fixed by means of a blepharostat; and, a small opening having been mado in the conjunctiva, the sclerotic was punctured on its outer side, between and posterior to the insertion of the external $/$ and inferior recti muscles. A brownish limpid fluid escaped from the wound. When it had ceased flowing the instrument was removed, and, without any sutures having been introduced into the conjunctital wound, the eye was closed, and an agglutinative dressing applied. The patient was ordered absolute rest. She took, every morning; a glass of aperient water.

On October 10th the dressing was removed, and as soon as she opened her eyes, the patient was astonished at the result of the operation. She could count the fingers, see the whole length of them, and distinguish between two diferent coins of the same colour.

On October 12th the dressing was again removed, and it was found that progress continued to be made. The patient cotild neald at a distance of 2 mètres $\frac{1}{8}$ of Woeker's type, with the eye that had boen loperated on, and she coald tell the time on watch.
Dr. Bacchi, chef de clinique, has taken the visual field, before, apd after the operation; wheh is shown in the map.

I have only to add, Mr. President, that the constitutional complications were conditions unfavourable to my operation. I undertook to operate under such circumstances, simply to demonstrate that we can so rotate the eyeball as to hring under the action of the instrument that portion of its posterior hemisphere towards which the effusion inclines, and so empty it completely whout interfering with the other tissues. But the result which S have obtained holds out the hope that, in emptying out the liquid' by sclenotomy, we have also succeeded in curing the patient of her glaucoma.

It is not without reluctance that I mention the operation known as scleral puncture, which, first proposed by Professor von Gräfe, has been practised for the cure of this affection. Many surgeons have practised it, but have been compelled to abaridon it. It consists simply in putting 2 cataract-knife through the conjunetiva and sclerotic, into what is considered to be the site of the detachment, The result is, that tumour, which is supposed to contain the effused serum, is formed under the conjunctiva. The fluid is allowed, for a fortnight or so, to absorb, and then, as a rule, very little or no result is obtained: mention this simply to point out that, in the first place, to thrut a knife into the eyeball in the hope of : effecting somethingo is not eye-surgery. This if not the way in which we attempt to remove fluid from other cavities. Furthef when the patient is put of his back, and under chlortoform, the power of rotation of the eyeball becomes i very liported, and the probability is; that the fluid falls back wards and, in many cases, there is reitioved, not the fused serum, but a portion of the vitreous. So long; there fore, as surgeons regard ' $m$ t o operation sinfoly as a subberí junctival sclerotomy, thejt chances of success will be comparatively small. My"systen must be -studied in its totalify. Two things in 'it 'are to be specially attended to, namely, the ophthalmoscopic examing? tion of the eye in various posstions; and the liberating of the eyeball from its envelope; 'so'ds to render' tisible, and 'brin's into proper position, that part behind the equator towation which the fluid inclines, apt also to demonstrate to ots serrses that the effustion and nothing but the effusion, been removed. If the opeta tion be so understoód and practised, it is certain to bic satisfactory in its results.

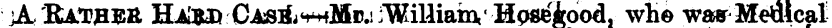
Officer of Health for tho Amenshim Raral Sanitiary District for the year ending 29th Septembor last, iwas then re-appointed by the aut thority for anothex cyerer, bht, the Loedl Government Board aboves notwithstanding thoy' had confirmed; the appointment for the previotis jegr, declined to do so : dgain, becanse (as we believe) he resided ottb side the district: Andther gentleman has now been appointed, attht, at the lastmeeting of the' Senitary Authority; a letter from $\mathbf{M r}$. Hoss good was read, asking' for a testimpnial, and for the payment of atlaty for the period duxing , which he!discharged the daties, from! the 29 th September to the Iith of Notrembers The clerk was directed to pref pare and forward a. testimbnial, Iand to inform him that they

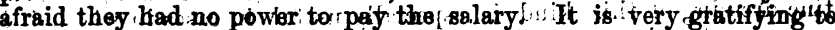

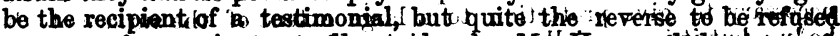

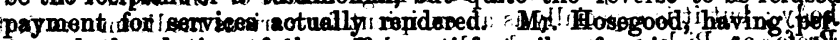

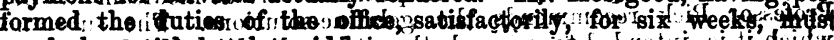

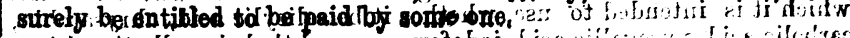

